Pedagogía y Saberes No. 50

Universidad Pedagógica Nacional

Facultad de Educación. 2019. pp. 211-221

\title{
Del mundo de lo sensible al universo de lo inteligible en la enseñanza de las ciencias naturales*
}

\section{Artículo de investigación}

From the World of the Sensible to the Universe of the Intelligible in the Teaching of the Natural Sciences Do mundo do sensível ao universo do intelegível no ensino das Ciências Naturais

Luz Dary González Villate**

Para citar este artículo:

González, L. (2019). Del mundo de lo sensible al universo de lo inteligible en la enseñanza de las ciencias naturales. Pedagogía y Saberes, 50, 211-221.

* Reflexión derivada de la investigación —en curso- que soporta la tesis doctoral titulada El deseo y la formación en el Doctorado Interinstitucional en Educación DIE-UPN.

** Estudiante de Doctorado en Educación de la Universidad Pedagógica Nacional DIE-UPN e investigadora del grupo Filosofía y enseñanza de la filosofía.

Correo electrónico: luzdaryvillate@gmail.com 


\title{
Resumen
}

Este artículo presenta una reflexión derivada de investigación en el que se argumenta que así como a la filosofía, a la enseñanza de las ciencias le asiste un doble compromiso: ocuparse de los principios que orientan su actividad (pedagogía) y comprender la gramática de las disciplinas que se propone enseñar (química, física, biología, matemáticas). Respecto al primer compromiso, se argumenta que-durante su formación- el educando establece relaciones con el saber de orden imaginario, simbólico y real, en las que los semblantes de saber del maestro - saber supuesto, expuesto, en reserva y deseo de saber- se constituyen en condición de posibilidad del deseo de saber del educando. En cuanto al segundo compromiso, se exponen algunas reflexiones epistemológicas frente a la tensión presente en las relaciones: experiencia-experimento, experienciaformalización, serendipia-experimento y artefacto-instrumento, para concluir que, en la enseñanza de las ciencias, se transita del mundo de lo sensible al universo de lo inteligible.

\section{Palabras clave}

enseñanza de las ciencias; registros Lacan; deseo de saber; mundo sensible; universo inteligible

\begin{abstract}
This article presents a reflection derived from research in which it is argued that as well as philosophy, the teaching of science is assisted by a double commitment: to deal with the principles that guide its activity (pedagogy) and to understand the grammar of the disciplines it intends to teach (chemistry, physics, biology, mathematics). Regarding the first commitment, it is argued that-during its formation-the student establishes relations with the knowledge of imaginary, symbolic and real order, in which the semblances of knowledge of the teacher-said course, exposed, in reserve and desire to know - they constitute a condition of possibility of the learner's desire to know. Regarding the second commitment, some epistemological reflections are exposed in front of the tension present in the relations: experience-experiment, experience-formalization, serendipity-experiment and artefact-instrument, to conclude that, in the teaching of sciences, the world of the sensible to the universe of the intelligible.
\end{abstract}

\section{Keywords}

science education; Lacan records; desire to know; sensible world; intelligible universe

\section{Resumo}

Este artigo apresenta uma reflexão derivada de uma pesquisa na qual se argumenta que, assim como a filosofia, o ensino de ciências é auxiliado por um duplo compromisso: ocupar-se com os princípios que norteiam a sua atividade (pedagogia) e compreender a gramática das disciplinas que pretende ensinar (química, física, biologia, matemática). Em relação ao primeiro compromisso é argumentado que — durante a sua formação—o aluno estabelece relações com o saber da ordem imaginária, simbólica e real, em que os semblantes de saber do mestre - saber suposto, exposto em reserva e desejo de saber-constituem-se em condição de possibilidade do desejo de saber do aluno. Em relação ao segundo compromisso, algumas reflexões epistemológicas são expostas diante da tensão presente nas relações: experiência-experimento, experiência-formalização, serendipidade-experimento e artefato-instrumento, para concluir que, no ensino de ciências, transita-se do mundo sensível ao universo do inteligível.

\section{Palavras-chave}

educação científica; Registros de Lacan; desejo de conhecer; mundo sensível; universo inteligível 


\section{Introducción}

$\mathrm{P}$ ara Lacan (2012, p. 539): “Una práctica no tiene necesidad de ser esclarecida para operar", de tal suerte, los hombres de ciencia, para llevar a cabo su tarea como científicos, no necesariamente deben ser filósofos o historiadores ${ }^{1}$; no obstante, en La filosofía del no. Ensayo de una filosofía de un nuevo espíritu científico (Bachelard, 2003), el autor indica que a la filosofía le asiste un doble compromiso: ocuparse de los principios que orientan su actividad y comprender la gramática de las disciplinas que se dispone analizar, sin olvidar que:

La utilización de los sistemas filosóficos en dominios alejados de su origen espiritual es siempre una operación delicada, y a menudo una operación abusiva. Así trasplantados, los sistemas filosóficos se vuelven estériles y falaces, pierden su eficacia como coherencia espiritual, eficacia tan palpable cuando son revividos en su originalidad real [...]. Habría que concluir, pues, que un sistema filosófico no debe ser utilizado para otros fines que aquellos que él mismo se asigna. Por consiguiente, la falta más grave contra el espíritu filosófico sería precisamente desconocer esta finalidad íntima, esta finalidad espiritual que da vida, fuerza y claridad a un sistema filosófico. (Bachelard, 2003, p. 7).

La finalidad de la que habla Bachelard, en relación con la gramática filosófica, dista - y se distingue - de los propósitos que se trazan los sujetos que intervie-

1 Para el asunto que nos convoca, la afirmación de Lacan me sugiere que la práctica científica - y, en consecuencia, sus productos- es indiferente a los enunciados proferidos por disciplinas tales como la historia o la sociología de las ciencias. Es decir, que la producción de enunciados en el campo científico (leyes, teorías) es sincrónica y depende exclusivamente de su gramática y de las tensiones propias del campo, en cuyo caso, lo dicho desde la sociología o la historia se constituiría más bien en "presiones" que no modifican de ninguna manera su naturaleza, así como la presión atmosférica perfila la forma de una gota de agua, pero no modifica su composición química. Es el caso, por ejemplo, del Teorema de Fermat, el cual fue conjeturado en 1637 y cuya demostración fue completada hasta 1994, luego de tres siglos y medio de trabajo de varias generaciones de matemáticos. Aquí, la temporalidad y las condiciones de posibilidad en las que se inscribieron la postulación y la consecuente demostración del teorema son concebidas de manera distinta desde la matemática, la historia o la sociología. Matemáticamente hablando, la temporalidad a la que me refiero, entre la postulación y la demostración del teorema, se subordina a los desarrollos propios de la teoría de números (tiempo lógico); mientras que histórica y sociológicamente hablando, esta temporalidad se subordina a los hechos y a las condiciones en las que habita la comunidad científica (tiempo cronológico). De igual manera, la fisión nuclear que hizo posible la bomba atómica se hubiera realizado indefectiblemente (realización en sentido bachelardiano), independientemente de las intenciones subjetivas de aquellos que intervinieron en el Proyecto Manhattan. nen; ello correspondería más a una pragmática. La finalidad íntima y espiritual a la que hace referencia nuestro autor tiene que ver con la gramática que ordena y estructura el sistema filosófico del que se trate. Así, cuando se utiliza o se traslada un sistema filosófico a dominios alejados de su origen, opera algo radicalmente distinto. Cuando la historia, la filosofía o la sociología se disponen a ordenar, comprender epistemológica o socialmente las condiciones de posibilidad del trabajo científico, se está trabajando desde otras ciencias; pero en ningún caso desde las ciencias naturales como para afectar estructuralmente su campo de producción simbólica. En estos campos, sus finalidades inmanentes responden únicamente a sus propias gramáticas (Bachelard, 2003).

Dicho de este modo, nos es lícito afirmar que algo parecido le acontece a la enseñanza de las ciencias, en donde - como en la filosofía de las ciencias- se trabaja con saberes alejados de su origen espiritual (Bachelard, 2003), ya que, tanto la física, como la química y demás ciencias naturales son disciplinas construidas dentro del campo científico ${ }^{2}$. En este caso, podríamos decir que a la enseñanza también le asiste un doble compromiso: ocuparse de los principios que orientan su actividad (pedagogía) y comprender la gramática de las disciplinas que se propone enseñar a los más jóvenes (química, física, biología, matemáticas).

Tomando en cuenta lo anterior, me propongo, en lo que sigue, esbozar brevemente algunas consideraciones en relación con estos dos compromisos.

\section{Algunas consideraciones sobre la enseñanza}

Distinto a lo que suele ser aceptado en diversas investigaciones en torno al aprendizaje, la aproximación inicial a una disciplina no se hace precisamente a partir de un deseo y de una curiosidad natural ${ }^{3}$. Si

2 Alguien podría sugerir que los campos de la ciencia y de su enseñanza se interceptan en una región que podríamos llamar saberes científicos a enseñar; no obstante, esta mirada - y la selección de saberes que comportaría dicha interseccióntiene una especificidad distinta a la de los campos en cuestión. Las gramáticas propias de la actividad que le comporta a cada campo - las tensiones- no comparten mutuamente su naturaleza. En la escuela, los estudiantes no hacen ciencia, hacen algo de no menor valía, de una valía propia del campo educativo: aprenden ciencias; asimismo, para el físico cuántico lo enseñable no es una cuestión estructural en el devenir de los saberes producidos a partir de las colisiones dentro de un acelerador de partículas.

3 En este texto, el deseo de saber no se constituye en una condición natural del sujeto hablante, se distancia de lo necesario y no debe confundirse con el amor o la admiración que podrían 
este fuera el caso, la "curiosidad innata" del educando sería el vehículo ideal en la inserción de aquel en la cultura y serían prescindibles el maestro y la escuela; no obstante, no es el caso y sabemos que la enseñanza comporta ciertas complejidades en relación con los sujetos que intervienen. $\mathrm{Al}$ respecto, cabe reconocer que a la escuela, además de su estructuración alrededor del saber, le subyace como elemento fundamental el establecimiento de un vínculo entre sujetos; sujetos que, por una parte, encarnan el lugar de el que sabe-maestros-, y sujetos que, por otra parte y por estructura, no desean saber ${ }^{4}$ - alumnos-; es decir, la labor del maestro, si bien se define en torno a un saber, enfrenta al mismo tiempo la responsabilidad de hacerse cargo de otro y de configurar un vínculo con aquel que no sabe.

Pero, ¿de qué naturaleza es ese vínculo?

Si se indagara entre los estudiantes por la manera en la que brotó su interés - o desinterés- hacia determinada disciplina, sería posible reconocer el papel de sus maestros, ya que generalmente la inquietud por un campo disciplinar no emerge puramente de su inteligibilidad; diríamos que en los estudiantes acontece al principio una relación imaginaria ${ }^{5}$ con sus profesores, y que esta desempeña un papel determinante en el vínculo del que estamos hablando; en tanto, ante ellos, se presenta alguien a quien se le

ser dirigidos hacia una disciplina; por el contrario, se trata de un deseo que emerge, no de manera natural, sino como el efecto de una contingencia.

4 Entiendo que la afirmación puede parecer trágica; no obstante, no podemos desconocer que en la formación inicial los estudiantes no-eligen estar allí, ya que se trata de una elección hecha por otros que generalmente son los padres, inducidos estos, a su vez, por la presión social y cultural, por el riesgo a las penalidades que comporta no llevar a sus hijos a la escuela, etc. De tal suerte que la condición a la que se enfrenta el maestro es ciertamente problemática: producir un deseo de saber en sujetos que, por estructura, no desean saber. Ahora bien, alguien podría decir: "ipero claro que los niños desean saber! ¡desean saber lo que sus compañeros piensan de él! ¡desean saber lo que tú guardas en tu cajón!...”; en cuyo caso, debo aclarar que el saber al que hago referencia es el saber disciplinar alrededor del cual se estructura la escuela (matemáticas, química, física, geografía...), lo cual demanda del sujeto que aprende, una disposición - disciplina, si se quiere- que no le es dada naturalmente (Kant, 2003).

5 Con relación imaginaria me refiero al tipo de vínculo que un sujeto establece con otro semejante, a partir de la imagen que se hace de este. En la escuela, y especialmente en la formación inicial, este tipo de relación es muy importante, ya que el niño puede tomar de este otro (maestro), rasgos de identificación determinantes en su constitución subjetiva. supone un saber. Como podemos inferir, no se trata de una relación entre pares, como se viene promoviendo actualmente $^{6}$.

Dicha suposición de saber, no sin dejar de lado las acciones que se llevan a cabo en la escuela en relación con el cuidado y la disciplina, se ve confirmada o rebatida en tanto el maestro expone ante el niño el saber que inicialmente este le supone. Diríamos que en el momento imaginario inicial le acontece ${ }^{7}$ un tipo de relación simbólica ${ }^{8}$, en la que lo expuesto por el maestro prepara el terreno para que el estudiante establezca una relación con el saber. Pero dicha exposición, si bien se soporta en enunciados y en productos de la disciplina, no se reduce a estos, ya que junto con su exposición, el maestro exhibe su propia relación con este saber. De esta manera, un maestro que muestra una relación de gusto, amor, horror o deseo podría a su vez tener efectos de formación concomitantes en sus estudiantes, los que, según sea el caso, manifestarán un "yo quiero de eso" que el maestro encarna, como intercambio de su propio régimen de satisfacción. Es decir, que la fascinación por una disciplina pasa inicialmente por desear tener "eso" de lo que el otro goza; y no hablo de un rasgo material o de un saber sabido, sino de un desear que es acicateado, no por una espetada total del saber que bien podría aplastar y consumir el deseo, sino a partir del juego de seducción conjurado por el maestro entre su saber expuesto y un saber que él mantiene en reserva.

6 Si ahondáramos más en las implicaciones que puede tener una relación de identificación imaginaria en el lazo social que se crea entre maestro y estudiante en la escuela, reconoceríamos los efectos devastadores que tiene, para el sujeto, la promoción de relaciones de horizontalidad y de remoción de límites que se promueve hoy. Entre los efectos de los que hablo podemos contar: la dejación del saber como referente de formación, que el maestro ya no represente nada ante el niño (la cultura, por ejemplo), que se establezca una relación meramente imaginaria entre semejantes imposibilitando el paso a lo simbólico, entre otras.

7 Llegados a este punto, quiero aclarar que los momentos de los que vengo hablando no se suceden linealmente, ni se comprenden como etapas, periodos o ciclos. Más bien se trata de condiciones que, teniendo como horizonte al saber, subyacen al vínculo maestro-estudiante y que, las dos primeras, podrían darse simultáneamente.

8 La relación simbólica de la que hablo se refiere al encuentro del sujeto con el Otro de la cultura a través del maestro. Quiero decir que el maestro, al exponer el saber que se le supone, de una u otra manera está poniendo al estudiante en relación con ello, constituyéndose en representante de esa Otredad que es la cultura. 
En este orden de ideas, diríamos que la postura del maestro implica un semblante de saber que transita por un saber supuesto, un saber expuesto, un saber en reserva y un deseo de saber encarnado.

Bien. Si desde esta perspectiva consideramos un tipo de sujeto como el concebido por Kant (2003) en su Tratado de pedagogía - un sujeto que requiere cuidados y disciplina para ser instruido y, posteriormente, alcanzar su mayoría de edad-, podríamos afirmar que a la educación le corresponden dos tareas: formar (cuidar y disciplinar) e instruir, teniendo como horizonte de la educación que el sujeto - alcanzando su mayoría de edad- pueda valerse por sí mismo prescindiendo y liberándose de la conducción y de la coacción del otro, asistiendo, a su vez, a una relación con el saber en el orden de lo real' ${ }^{9}$.

Así las cosas, de lo anterior podríamos deducir que si la aspiración de toda educación es "la emancipación de los hombres de su merecida tutela" (Kant, 2004, p. 33), entonces, la libertad del sujeto sería una conquista y el maestro vería consumada su tarea cuando el educando deje de necesitarlo para ir en pos de su propio deseo de saber.

Volviendo sobre el propósito de nuestro texto, en lo que sigue, arriesgaré algunas consideraciones en relación con la enseñanza de las ciencias naturales, desde cierta comprensión epistemológica de su gramática.

\section{Enseñanza de las ciencias naturales}

Uno de los más apasionantes capítulos de la filosofía de las ciencias es el dedicado a esclarecer la inquietud de si la actividad científica se soporta en la experimentación y auscultación del mundo físico o en la abstracción y consecuente formalización de las ideas; de manera análoga, la historia de las ciencias sugiere un continuo bascular entre las ciencias como una autopsia de la naturaleza y las ciencias como una teorización de esta.

9 Quiero plantear este tipo de relación con el saber en el orden de lo real, en tanto el sujeto abandona los referentes imaginario y simbólico que le provee la escuela. Es decir, el sujeto se relaciona con el saber en tanto este es objeto de su deseo singular. Por supuesto que en el orden de lo real hay una separación del otro que hace que el sujeto invente — para sí- una relación en la que acepta que no hay saldo de saber y que algo del saber no puede saberse; en cuyo caso, dicha imposibilidad instiga al trabajo: como si lo imposible - por imposibleobrara como provocación. Provocación que inevitablemente dejará efectos de saber a su paso.
Tal inquietud no está ausente en discusiones en torno a la enseñanza de las ciencias, ya que, si se les pidiera a los educadores aventurar una definición de ciencias naturales, nos toparíamos con la imposibilidad de declararlas absolutamente experimentales o absolutamente formales.

No obstante, hay también quienes afirman que la ciencia es una amplia, llana y continua actividad humana de construcción de explicaciones, consintiendo, en consecuencia, que pueda albergar tantas miradas como sujetos o regímenes de verdad sea posible imaginar. Tal postura culturalista se apoya en una mirada sociológica de las ciencias que afirma que los productos de la ciencia son efecto de sus condiciones históricas, sociales, políticas y religiosas; en ella no se distingue con claridad una gramática propia a la ciencia; $\mathrm{y}$-de acuerdo con la consigna que sustenta esta postura: la ciencia como una actividad cultural de construcción de explicaciones - los seres humanos, sin distinción, serían científicos potenciales (los integrantes del Proyecto Manhattan, los indígenas en la preparación de sus medicinas ancestrales y los niños - o sus maestros-en las clases de ciencias).

Al respecto, declaro mi distanciamiento de esta postura, ya que su pretensión iguala gramáticas y pragmáticas de naturaleza distinta. Debo decir, en su lugar, que si bien el principio de atribución precede al principio de existencia (Freud, 1996), la ciencia es una suerte de atribución obligatoriamente aceptada; ya que los hombres de ciencia se someten al trabajo con una gramática que, si bien no existiría sin ellos, los excluye como sujetos. En las ciencias naturales, la gramática opera indistintamente del hombre de ciencia que las hace posibles; paradójicamente, dicha exclusión es necesaria para que esta gramática pueda fecundarse.

Tomando en cuenta lo anterior, en lo que sigue plantearé algunas reflexiones epistemológicas a partir de la tensión emergente en las relaciones experiencia-experimento, experiencia-formalización, serendipia-experimento y artefacto-instrumento; lo anterior, soportado en la consideración de que, en la enseñanza de las ciencias, se transita del mundo de lo sensible al universo de lo inteligible.

\section{Experiencia y experimento}

En los primeros años de educación básica, los maestros de ciencias naturales suelen reconocer la importancia y la necesidad de la vivencia fenoménica del mundo y de su aproximación a través de los sentidos, apelando a una transformación continua desde lo 
que se suele denominar "conocimiento común", atravesando el "conocimiento escolar" y finalmente arribando al anhelado "conocimiento científico"; no obstante, se hace necesario reconocer que tal continuidad progresiva no existe, y que pensarla como tal, inevitablemente nos enfrenta a obstáculos epistemológicos ${ }^{10}$ de difícil solución, tales como la opinión, la experiencia básica, la extensión abusiva de las imágenes familiares, el conocimiento meramente utilitario y pragmático, entre otros (Bachelard, 1981), solo por mencionar aquellos que animan una falsa continuidad.

Para Bachelard (1981) no hay continuidad entre el conocimiento común y el conocimiento científico: hay una ruptura epistemológica entre el mundo de lo sensible -territorio del conocimiento común-y el universo de lo inteligible ${ }^{11}$-imperio del conocimiento científico-; no obstante, se hace necesario destacar que a esta idea bachelardiana no le asiste una subvaloración del conocimiento común frente al científico, de manera que no es posible pensar en un progreso entre uno y otro, ya que cada uno de ellos resuelve lo que le es propio, según sea el caso.

Si el asunto de la formación y de la instrucción en ciencias naturales no versa solo en la llana recreación de la sensación -ya Descartes (2005) nos advertía de su engaño-, entonces, cobra relevancia la pregunta por el fundamento del modelo explicativo. Quiero decir: si en la formación básica, la propuesta se plantea desde de lo sensible, entonces: ¿qué lugar ocupa lo inteligible?

Es cierto que la simplificación de la rigurosidad formal no es nada menos que la recontextualización connatural al acto pedagógico; sin embargo, vale la pena preguntarse por el tipo de recontextualizaciones que se hacen, ya que, en la mayoría de los casos, estas se hacen a nombre de la sensibilidad y distan drásticamente de su horizonte de inteligibilidad, entonces, se hace imperativo fijar la mirada en el cambio epistemológico que subyace entre lo sensible y lo inteligible en la enseñanza de las ciencias naturales.

10 La noción de obstáculo epistemológico fue acuñada por Bachelard (1981) con el fin de describir algunos elementos de orden "espiritual" (postura científica) que impiden el encuentro con ideas de orden objetivo y no referidas propiamente a la experiencia sensible e inmediata.

11 Esta oposición entre mundo sensible y universo inteligible la hago inspirada en el texto Del mundo cerrado al universo infinito de Alexandre Koyré (1979), a través del cual, el autor logra dibujar con filigrana el tránsito de la astronomía griega a la física newtoniana.
En ese orden de ideas, la reflexión histórico-epistemológica de una disciplina científica es menester para su enseñanza, ya que la edificación de la disciplina y su consecuente transformación determinan sustancialmente modelos explicativos de recontextualización. La enseñanza de un saber disciplinar, lejos de ser una mera transmisión de contenidos, discurre en la comprensión epistemológica de su fundación.

Un contexto de enseñanza puede constituirse en un espacio que da lugar a la comprobación de teorías o puede ser el efecto de preguntas desencadenantes de una gramática. Según Bachelard (2003), el devenir de un curso orientado a comprender las ciencias naturales depende de las preguntas con las que se espera seducir e interpelar al neófito. Así, la noción de observación, la consecuente pregunta por su estatuto epistemológico y la postura que se encarne frente a cuestiones tales como: ¿qué es un experimento?, ¿comprueba este una teoría?, ¿cuál es la diferencia entre experiencia y experimento?, ¿cuál es la diferencia entre explicación cualitativa y explicación cuantitativa?, ¿cuáles son los alcances y las limitaciones de la experiencia?, resultan determinantes para el maestro.

Instalados en la pregunta por el lugar que ocupan la experiencia y el experimento en la enseñanza de las ciencias, nos encontramos - guardadas las proporciones- frente a una de las polémicas disertaciones de las cuales han sido protagonistas grandes epistemólogos de la talla de Kuhn (1971), Bachelard (1981), Canguilhem (1986) y otros, de cara a ciertas posturas epistemológicas tendientes a considerar la inexistencia de una línea de diferenciación - y separación-entre experiencia y experimento. Empero, existe un abismo epistemológico entre ambos, ya que, en resumidas cuentas, la experiencia se encuentra dada para el sujeto en la vivencia simple, sin pregunta, sin intención alguna por comprender el mundo; mientras que el experimento está referido a la intención expresa de obligar a la naturaleza a comportarse como, de antemano, lo advierte una teoría, exigiendo el sometimiento a una gramática que da lugar a la elaboración, la creación y la calibración de instrumentos. En otras palabras, la experimentación está subordinada a la razón. La teoría dicta al experimentador qué medir, qué observar.

Llegados a este punto, permítanme junto con Bachelard (1981), llamar la atención en que, para formar un espíritu científico, hace falta antes que instruir en la cultura científica, conmover la postura del sujeto: 
En la educación, la noción de obstáculo pedagógico es igualmente desconocida. Frecuentemente me ha chocado el hecho de que los profesores de ciencias, aún más que los otros si cabe, no comprendan que no se comprenda. [...] Los profesores de ciencias se imaginan que el espíritu comienza como una lección, que siempre puede rehacerse una cultura perezosa repitiendo una clase, que puede hacerse comprender una demostración repitiéndola punto por punto. No han reflexionado sobre el hecho de que el adolescente llega al curso de Física con conocimientos empíricos ya constituidos; no se trata, pues, de adquirir una cultura experimental [experimento], sino de cambiar una cultura experimental [experiencia], de derribar los obstáculos amontonados por la vida cotidiana. (Bachelard, 1981, p. 20).

\section{Experiencia y formalización}

En la recontextualización de las ciencias naturales, no solo se suelen suponer falsas continuidades entre la vivencia experiencial y el experimento reificado, sino que además se ponen en evidencia otro tipo de contradicciones referidas a la teorización y a la formalización.

En numerosos planes curriculares ${ }^{12}$, la física y la química no ocupan un lugar preponderante hasta el grado décimo de la educación media, bajo el supuesto de que es necesario agotar previamente la matemática de grado noveno (álgebra), para así poder aprehenderlas. No obstante, si bien la rigurosidad de la formalización es necesaria, esta no desplaza la posibilidad de que en los primeros grados de formación, puedan establecerse relaciones de proporcionalidad entre magnitudes físicas. En efecto, las ideas científicas son ya, de por sí, relaciones; como ya nos lo había enseñado Arquímedes, mucho antes que el impresionante Galileo ${ }^{13}$. En la escuela suele

12 Los planes curriculares a los que me refiero son - en su mayoría - aquellos implementados en las escuelas públicas de Bogotá (Colombia).

13 Alexandre Koyré (2005), en sus Estudios galileanos, ubica a Arquímedes como precursor cardinal del proyecto galileano. Y esto no es de poca valía, en tanto se acepta que este se constituye en la joya de la corona de una transformación espiritual, en la que la vida contemplativa le dio paso a la vida activa, en la que el hombre dejó de contemplar la naturaleza para hacerle confesar sus secretos. Para Koyré (2005), la formalización de las ideas - ese maravilloso matrimonio entre filosofía natural y matemática- tiene su génesis en Arquímedes, superando así, epistemológicamente, a Galileo. Koyré (2005) comenta así — con fascinación — la gesta arquimediana: “DDe dónde viene esta curiosa física mecánica — todos los movi- considerarse que el conocimiento del mundo físico depende de la restricción que le imprime la destreza matemática y por ello se enseña en los últimos años de secundaria; sin embargo, la comprensión del fenómeno no siempre exige un aparato matemático sofisticado, así exista un abismo epistemológico entre la experiencia común y la formalización objetiva de esa experiencia.

En la escuela, el establecimiento de relaciones, su correspondiente ponderación, la correlación de variables, el establecimiento de condiciones específicas para un evento natural, la modelación e idealización de un fenómeno... son ya un intento por operar con una gramática y este puede no implicar el uso de los cálculos diferencial, integral, vectorial o de álgebra lineal.

Por otra parte, cabe señalar que si bien para el maestro la actividad científica no es de su completo desconocimiento, este no opera directamente con la gramática dela disciplina que enseña, opera con su

mientos de los cuerpos, dice con bastante frecuencia Galileo, pueden ser reducidos al principio de la balanza- e hidromecánica que hemos percibido en Benedetti y que acabamos de encontrar en Galileo? Lo hemos dicho ya varias veces: proviene directamente de Arquímedes, cuyo nombre no escribe jamás Galileo sin acompañarlo de los más elogiosos epítetos, y bajo cuya autoridad se va a poner. Con toda razón, sin duda alguna. Por otra parte, no fue Galileo el único que admiró por encima de todo a Arquímedes. Desde que Tartaglia edita sus obras en latín, su gloria, primero, y su influencia, después, no hacen más que crecer. Hasta tal punto que Cardano, quien muy seriamente se entretiene en clasificar a los grandes hombres por orden de preeminencia, asigna el primer lugar — por encima de Aristóteles - a Arquímedes, único en su categoría. [...] iponer a este artesano por encima de Euclides, por encima de Aristóteles! [...] En cuanto a la influencia, está muy claro que los dos mejores mecánicos de la época, [...], deben lo más lúcido de su pensamiento a Arquímedes. Y en cuanto a Galileo, puede decirse, por expresarlo de alguna manera, que se formó en la escuela de Arquímedes. En efecto, es con la Bilancetta-tratado de la balanza hidrostática- con la que el joven Galileo se inicia en la vida científica; y su primera cátedra de matemáticas en la Universidad de Pisa la debe a un trabajo sobre el centro de gravedad de los sólidos, de inspiración y técnica totalmente arquimedianas; y es afiliándose consciente y resueltamente a la escuela de Arquímedes, abrazando la tradición del pensamiento que este representa - a favor de los "antiguos" y en contra de Aristóteles - como Galileo llega a superar la física de la fuerza impresa y se eleva al nivel de la física matemática, que no es otra cosa sino una dinámica arquimediana. [...] Una física arquimediana quiere decir una física matemática deductiva y "abstracta": tal será la física que Galileo desarrollará en Padua. Física de la hipótesis matemática, física donde las leyes del movimiento, la ley de la caída de los graves, son deducidas "abstractamente" sin hacer uso de la noción de fuerza, sin recurrir a la experiencia de los cuerpos reales" (Koyré, 2005, p. 68). 
recontextualización ${ }^{14}$, al desconocer por sí mismo, la labor propia del científico. El maestro de ciencias no hace ciencia en el aula; pero exhibe su relación con el saber. Dificulta al estudiante poniendo en problemas su régimen de satisfacción, ofreciéndole en su lugar, un objeto de satisfacción inteligible; enseñando a pensar físicamente; enseñando una manera de pensar; enseñando la gramática de una disciplina.

\section{Serendipia y experimento}

Hace algunos meses, revisando algunas de las anécdotas tejidas alrededor de ciertos "descubrimientos" científicos, encontré que estas suelen ser narradas adjudicando a la serendipia un papel protagónico ${ }^{15}$. Recordé la frase de Louis Pasteur: "la casualidad solo favorece a las mentes preparadas" y pensé en los efectos que podría tener, para la enseñanza de las ciencias, la llana certificación dela espontaneidad y de la casualidad como precursoras de los hallazgos científicos.

Y es que, si bien el llamado contexto de descubrimiento no siempre es tan claro, afirmar ostensiblemente que las ideas científicas son fruto del azar y de la espontaneidad no es tan cierto. Agenciar esta postura en la escuela tributaría, de la misma manera, al carácter antiespiritual —en sentido bachelardianoy pueril de la "ciencia" eléctrica del siglo XVIII ${ }^{16}$, en el

14 Podríamos afirmar que el maestro opera con más de una recontextualización; ya que la suya es una recontextualización de la recontextualización que hizo su maestro de universidad. Esto sin contar con las recontextualizaciones hechas en los libros de texto - suponiendo que el maestro haga uso de ellos-, las cuales muchas veces responden a políticas gubernamentales, a las ventas de las editoriales o a las planeaciones que piden las instancias administrativas de las instituciones educativas. No obstante, cabe aclarar que en la escuela, la recontextualización es inevitable, aun para aquellos maestros que operan también en el campo de producción; ya que su relación no solo es con el saber, sino con el otro-estudiante. Así, lo que determina el grado de recontextualización del maestro es su proximidad con el saber.

15 Anécdotas tales como aquella que aduce que la caída de una manzana sobre la cabeza del físico Isaac Newton fue el motivo principal para engendrar la magnífica idea de la gravitación.

16 En la Francia de finales del siglo XviII, era usual toparse en los bailes y encuentros sociales de ciertas clases acomodadas, con exposiciones y muestras de experiencias eléctricas en las que el espectáculo y la magia eran los protagonistas; es el caso, por ejemplo, de la experiencia denominada Los conjurados en la que, mediante un alambre de hierro, se provocaba la sacudida de cientos de personas. En ese mismo orden de ideas, del espectáculo y la sorpresa, la botella de Leiden (dos finas láminas metálicas que se separan debido a la repulsión eléctrica) provocó gran admiración, cuando muchas personas en casi todos los países de Europa, se ganaron la vida mostrándola que la futilidad de la sorpresa y lo pintoresco de la imagen se imponían ante el rigor y la trascendencia propios de la investigación científica ${ }^{17}$.

Es posible que algo de incertidumbre se encuentre en las investigaciones expuestas en los escritos originales de algunos hombres de ciencia, pero dicha incertidumbre, propia de la investigación, es en cierto modo controlada y no es posible abonarle todo el crédito, ni siquiera la mayor parte, a la casualidad plena. El azar no tiene un papel protagónico en el descubrimiento científico. La investigación es intencionada, aunque no necesariamente sus hallazgos; estos dependen más de la gramática que del azar ${ }^{18}$. Aunque el azar se oponga a lo "esperable", este se encuentra incorporado a la razón.

El desbordado interés de Galileo por lo supralunar y sus encuentros analíticos al respecto, lo condujeron a observar las lunas de Júpiter, las manchas solares y los cráteres de la Luna. Por ello, fundamentalmente, tomo distancia de la postura - bastante difundidaque propone a la casualidad como condición de posibilidad en el trabajo investigativo de las ciencias naturales. Cuando en las ciencias físicas se extrae el aire de una campana de vidrio, con el fin de producir un vacío imposible en nuestra atmósfera, o cuando en química se crean elementos que no existen de manera pura en la naturaleza (como el caso del americio, del tecnecio y de otros elementos radiactivos), se obliga a la naturaleza a comportarse de cierta manera. La gesta galileana consistió, justamente, en la pregunta con la que Galilei interrogó al cielo. Se abandonó la contemplación griega del cielo y se abrazó la formalización matemática de las ideas. El experimento

en todas partes; de igual manera, lo hizo la araña eléctrica, en la que "lejos de ir a lo esencial se aumentó lo pintoresco", fijando alambres en una esfera de médula de sauco. Particularmente, frente esta muestra de espectáculo, Bachelard (1981, p. 40) manifiesta que "es siguiendo un movimiento epistemológico inverso, volviendo hacia lo abstracto, arrancando las patas de la araña eléctrica, como Coulomb encontrará las leyes fundamentales de la electrostática".

17 A veces la enseñanza de las ciencias, fuertemente en los primeros años, se encuentra rebosada de experiencias que, como en el siglo XVIII, anteponen el espectáculo a la razón.

18 Es, por ejemplo, el caso del Positrón, el cual fue postulado por Paul Dirac en 1928 como la "otra solución": la solución positiva de una raíz cuadrada. Para lo cual - en su momento- no hizo falta un excelente laboratorio, sino saber que una raíz cuadrada tiene dos soluciones. Es cierto que inicialmente no fue una prueba empírica la razón de su existencia; pero fue la gramática - y no el azar- quien realizó esta partícula, descubierta hasta 1932 por el físico estadounidense Carl David Anderson al fotografiar las huellas de los rayos cósmicos en una cámara de niebla. 
se conjuró como una manipulación de lo natural. Experimentar fue entonces obligar a la naturaleza a comportarse tal y como el científico lo había pensado... obligar a la naturaleza a confesar sus secretos:

Preparar ese espacio para la ocurrencia del fenómeno aislado implica comprender la forma como actúan ciertas variables que han de ignorarse, pero también implica emplear medios adecuados que en algunos casos pueden ser muy sofisticados. Galileo empleó siempre herramientas muy simples para aislar los fenómenos o hacer despreciables las influencias que debían descartarse. En todo caso, el fenómeno aislado raras veces se da en la naturaleza cuando y como queremos verlo; es necesario construirlo. [...] El experimento es un fenómeno que responde a una pregunta precisa formulada desde la teoría. (Hernández, 2004, p. 103).

En las ciencias naturales no es la casualidad llana la que da origen y cuerpo a las ideas científicas. Al experimento científico lo precede una pregunta y esta pregunta lo conduce y lo engendra, sus resultados son legibles a la razón. La razón lee el experimento y lo concluye; él, por sí solo, no dice nada. En el campo científico, todos y cada uno de sus enunciados son intencionados, en cuyo caso, el experimento y sus instrumentos se constituyen en efecto de una comprensión teórica previa.

\section{Artefacto e instrumento}

Aparecen en la clase de ciencias gran cantidad de instrumentos cumpliendo una función específica; no obstante, se desconocen las razones para su construcción. Puede ser que para la enseñanza de las ciencias no resulte determinante, ni útil comprender su devenir como instrumentos; pero debo confesar que, en el deseo de aclarar el quehacer de las disciplinas, resulta fascinante conocer cómo se dio su emergencia, ya que los instrumentos, en cada una de sus versiones temporales, son testigos silenciosos de un resplandor en la historia de las ideas, al ser -en sí mismos- la materialización de una teoría... ¡una teoría realizada!

A la transformación de un artefacto en instrumento científico le subyace una idea nueva, una teoría emergente. Un objeto deja de serlo que era cuando es usado como instrumento científico. Uno de los ejemplos más ilustrativos de la invención de un instrumento es la invención del perspicillum ${ }^{19}$, a partir de la conversión del catalejo en telescopio.

19 Perspicillum fue el nombre dado por Galileo (1984) a lo que hoy llamaríamos telescopio, cuando sorprendió a sus contemporáneos anunciando, en Sidereus Nuncius (el mensaje y
Se dice que los holandeses pudieron ser quienes ofrecieron el catalejo a la República de Venecia antes que Galileo - aunque hoy se dude de que hubieran sido los holandeses ${ }^{20}$-; no obstante, independientemente de quien haya ostentado el encargo, el "uso distinto" del catalejo alteró drásticamente su destino.

Para el profesor Hernández (2004):

La cuestión de quién descubrió el telescopio parece tener muchos aspectos. El problema del autor de los inventos y descubrimientos no es, en muchos casos, un asunto de fácil solución en la historia de la ciencia. Si con la palabra "telescopio" [catalejo] hacemos referencia al instrumento que tenía dos lentes y ocho aumentos que podía emplearse como arma de guerra o para ver a cierta distancia por diversión, podría recordarse que [...] el inventor pudo ser un desconocido artesano de Italia del siglo XVI, cuyo nombre muy probablemente no conoceremos jamás. Pero si cuando hablamos de telescopio pensamos en ese instrumento que tenía 30 aumentos con el que pudieron verse cosas nuevas en el Cielo como los satélites de Júpiter, debemos decir que fue Galileo quien lo inventó. Detrás de esto no está solo la cuestión del campo semántico de la expresión "telescopio" sino un problema filosófico [...] el problema de cuáles cualidades determinan lo que son las cosas, cuáles de esas cualidades dependen del modo como están constituidas y podrían llamarse esenciales y cuáles dependen de la relación que establecemos con ellas. (Hernández, 2004, p. 26).

Nunca nadie antes había visto con un telescopio de 30 aumentos. La innovación y lo "revolucionario" de Galileo resulta de ser el primero que, mejorando enormemente el anteojo, hace de él un instrumento científico. Solo a partir de Galileo, gracias a la academia de la cual hacía parte, la Academia de Los Linces, ese instrumento se llamará "telescopio" [...]. Marina pregunta qué se puede ver con eso. Maravillas, cabría responderle, maravillas [...]. Lo maravilloso es lo que no se ve a simple vista.

Lo que no se ve a simple vista es el objeto propio de la nueva ciencia [...]. La mirada radicalmente nueva de la ciencia moderna implicaba poner entre paréntesis la experiencia directa del mundo. (Hernández, 2004, p. 26).

el mensajero sideral), una serie de descubrimientos astronómicos determinantes que habían sido posibles gracias al uso astronómico de este instrumento.

20 Ya en 1590, Hans Martens - el padre de Zacarías Hansentenía un catalejo italiano, cuyo inventor pudo ser un desconocido artesano italiano del siglo XVI (Hernández, 2004, p. 26). 
Ahora bien, ¿quién inventó el telescopio como instrumento dispuesto para la observación de la esfera supralunar?, ¿Galileo? ¿Los holandeses? ¿O quizás nuestro desconocido artesano italiano del siglo Xvı?

Bien. Los holandeses usaron el catalejo - un instrumento con las mismas características técnicas que las del telescopio, al ser, inicialmente, el acoplamiento en un tubo de una lente convergente y otra divergente- como instrumento militar para, durante la guerra, espiar los movimientos del enemigo y ver, anticipadamente, la aproximación de sus barcos; no obstante, a pesar de que el artefacto era técnicamente similar al telescopio - un tubo con lentes dispuestos de cierta manera que permitía acercar las imágenes de los objetos distantes-, fue la función la que le dio vida al instrumento. Su función, lo que es un telescopio, solo fue posible cuando Galileo Galilei lo apuntó al cielo. El mismo artefacto - el catalejo- dejó de serlo para ser inventado de nuevo como telescopio cuando Galileo lo dirigió hacia la bóveda celeste. Un experimento es, pues, la fabricación de un fenómeno natural en condiciones controladas; y la ciencia, entonces, una fábrica de fenómenos.

\section{Coda}

La ciencia matemática de la naturaleza, que entra con Galileo en un proceso de desarrollo que no se ha detenido, no se construye sobre la experiencia cotidiana sino contra esa experiencia.

Hernández (2004, p. 17)

Lo que parece evidente para nuestros sentidos puede resultar fenoménicamente distinto a lo percibido por los sentidos de otros, distinto en precisión, por ejemplo; un modelo se propone, en cambio, como una representación que puede ser compartida; un modelo resulta ser un excelente recurso de aproximación hacia lo inteligible, aunque se deba romper con lo reportado por las sensaciones.

Un modelo es una manera de operar, de decir, de pensar, de aproximarse a la realidad y la estrategia que me permite asir el mundo; podemos afirmar, entonces, que lo que enseñamos en ciencias naturales son modelos, maneras de hablar del mundo.

Del modo en la que lo he venido exponiendo, la idea de observación también se transforma: una partícula es observada usando como lente la gramática; es observada por las huellas que deja a su paso, no al verla cara a cara. Al respecto, hace un tiempo me encontré, en una entrevista de San Martín (2016) a la doctora en matemáticas Marta Casanellas, con una frase del biólogo y matemático Joel Cohen: "Las matemáticas son el nuevo microscopio de la biología, y la biología es la nueva física para las matemáticas" y reconocí y reafirmé con esta esclarecedora frase la idea de que a todas las ciencias les subyace un racionalismo aplicado. Decir que las-matemáticasson-el-nuevo-microscopio-de-la-biología, cuando el microscopio ha sido el instrumento por excelencia de esta disciplina, es poner en pregunta la nominación de "experimentales" que solemos darles a estas ciencias, y decir que la-biología-es-la-nuevafísica-para-las-matemáticas es reconocer que hoy el campo de aplicación de las matemáticas de frontera, y que amplía el campo propio de las matemáticas, es la biología.

Ante la imposibilidad de juntar cuerpo y habla, significante y significado, palabra y cosa, simbólico y real... construimos aproximaciones y modelos que nos permitan cerrar la brecha, o, al menos, hacerla menos gigante. La matematización y la formalización resultan ser entonces una manera de referirse a lo natural, a lo natural inasible. A partir de su abstracción, podemos hacernos a una idea aproximada del mundo natural. Es el caso, por ejemplo, del modelo estándar de física de partículas, el cual ofrece a la ciencia una estrategia de estudio unificada de las fuerzas fundamentales - gravitacional, electromagnética, nuclear fuerte, nuclear débil-; a pesar de que hoy se encuentra experimentalmente incompleto, en tanto la comprobación de la existencia experimental del bosón de Higgs no ha sido suficiente ${ }^{21}$.

En ese orden de ideas, cuando nos referimos a la observación en la clase de ciencias naturales, nos referimos a una "observación" que trasciende lo sensible; es decir, a una idea de observación orientada por lo inteligible. En cuyo caso, la enseñanza de ciertos fenómenos - sonoros, ópticos, mecánicos...-, en los cuales la interacción sensible pudiera ser estimulada y conducente, no excluye de sus terrenos a estudiantes con discapacidad —-sordos, ciegos-.

Si la física y las ciencias naturales - en generalno son campos referidos exclusivamente a lo sensible, entonces, ¿de qué naturaleza son la matemática y la geometría, si es posible enseñarlas a estudiantes

21 En el modelo estándar de la materia, el bosón de Higgs permite explicar el origen de la masa de las partículas elementales. Sin embargo, la ciencia ha dado cuenta de su existencia solo matemáticamente, ya que se trata de una partícula muy inestable: se desintegra rápidamente. Su expectativa de vida media es del orden del zeptosegundo, una miltrillonésima parte de un segundo $\approx 10^{-21}$ segundos. 
ciegos, sin depender del dibujo de líneas y círculos?, ¿es la geometría un asunto de dibujos?, ¿no será, en su lugar, una gramática? Basta escudriñar en los Elementos de Euclides para corroborar que la geometría es una manera de hablar y que en ninguna de sus páginas originales los teoremas fueron recontextualizados a través de líneas, cuadrados, círculos o cosa semejante $^{22}$. Se puede mostrar que Aquiles le gana a la tortuga, pero se demuestra lo contrario.

Pero estas reflexiones en torno a la enseñanza de la matemática, aunque tengan aires de familia con las expuestas anteriormente, en relación con la enseñanza de las ciencias naturales, serán el objeto de otro escrito; en todo caso, como lo afirmaba al comienzo, "A la enseñanza también le asiste un doble compromiso: ocuparse de los principios que orientan su actividad (pedagogía) y comprender la gramática de las disciplinas que se propone enseñar a los más jóvenes (matemática)".

\section{Referencias}

Badiou, A. (2009). El concepto de modelo. Introducción a una epistemología materialista de las matemáticas. Buenos Aires: La Bestia Equilátera.

Bachelard, G. (1981). El nuevo espíritu científico. México: Nueva Imagen.

Bachelard, G. (1981). La formación del espíritu científico. Contribución a un psicoanálisis del conocimiento objetivo. Buenos Aires: Siglo XXI.

Bachelard, G. (2003). La filosofía del no. Ensayo de una filosofía de un nuevo espíritu científico. Buenos Aires: Amorrortu.

Blanché, R. (1972). El método experimental y la filosofía de la física. México: Breviarios del Fondo de Cultura Económica.

Canguilhem, G. (1986). Lo normal y lo patológico. Buenos Aires: Siglo XXI.

Corral, M. (2011). ¿Qué supondría el hallazgo de la "partícula de Dios"? Recuperado dehttp://www.elmundo. es/elmundo/2011/12/13/ciencia/1323778726.html

Descartes, R. (2005). Meditaciones metafísicas. Madrid: Alianza.

Euclides. (1982). Elementos. Madrid: Gredos.

22 Suelen encontrarse algunas de estas recontextualizaciones en ediciones tales como la referenciada en la bibliografía por la Editorial Gredos (1982); no obstante, dichas representaciones han sido trabajo confeso de los editores.
Freud, S. (1996). Formulaciones sobre los dos principios del acaecer psíquico. En J. Strachey (ed.), Obras completas, vol. XII (pp. 217-232). Buenos Aires: Amorrortu.

Galilei, G. y Kepler, J. (1984). El mensaje y el mensajero sideral. Madrid: Alianza.

Galilei, G. (1995). Diálogo sobre los dos máximos sistemas del mundo ptolemaico y copernicano. Madrid: Alianza.

González-Villate, L. (2012). La ciencia como discurso. ¿Un análisis semiótico de la física? (Tesis laureada de Maestría en Educación). Universidad Pedagógica Nacional, Bogotá.

Granés, J. (2001). La gramática de una controversia científica. El debate alrededor de la teoría de Newton sobre los colores de la luz. Bogotá: Unibiblos.

Guitart, R. (2003). Evidencia y extrañeza: matemática, psicoanálisis, Descartes y Freud. Buenos Aires: Amorrortu.

Hawking, S. (2010). El gran diseño. Barcelona: Crítica.

Hernández, C. (2004). Galileo: el arte de la ciencia. Bogotá: Impresol.

Kant, I. (2003). Pedagogía. Madrid: Akal.

Kant, I. (2004). Respuesta a la pregunta ¿qué es la ilustración? En E. Cassirer (ed.), Filosofía de la historia. ¿Qué es la ilustración? (pp. 33-40). La Plata: Terramar.

Koyré, A. (1979). Del mundo cerrado al universo infinito. Madrid: Siglo XXI.

Koyré, A. (1994). Pensar la ciencia. Barcelona: Paidós.

Koyré, A. (2005). Estudios galileanos. México: Siglo XXI.

Kuhn, T. (1971). La estructura de las revoluciones científicas. México: Breviarios del Fondo de Cultura Económica.

Lacan, J. (1997). El estadio del espejo como formador de la función del Yo (je) tal como se nos revela en la experiencia psicoanalítica. En A. Suárez (ed.), Escritos I (pp. 86-93). México: Siglo xxI.

Lacan, J. (2012). Televisión. En G. Trobas (ed.), Otros escritos (pp. 535-572).Buenos Aires: Paidós.

Locke, D. (1997). La ciencia como escritura. Madrid: Cátedra.

Newton, I. (1993). Principios matemáticos de la filosofía natural (prefacio). Barcelona: Altaya.

San Martín, J. (2016). Martha Casanellas: "Las matemáticas son el nuevo microscopio de la biología". Recuperado de https://mujeresconciencia.com/2016/05/04/martacasanellas-las-matematicas-son-el-nuevo-microscopiode-la-biologia/

Serres, M. (1991). Historia de las ciencias. Madrid: Cátedra. 


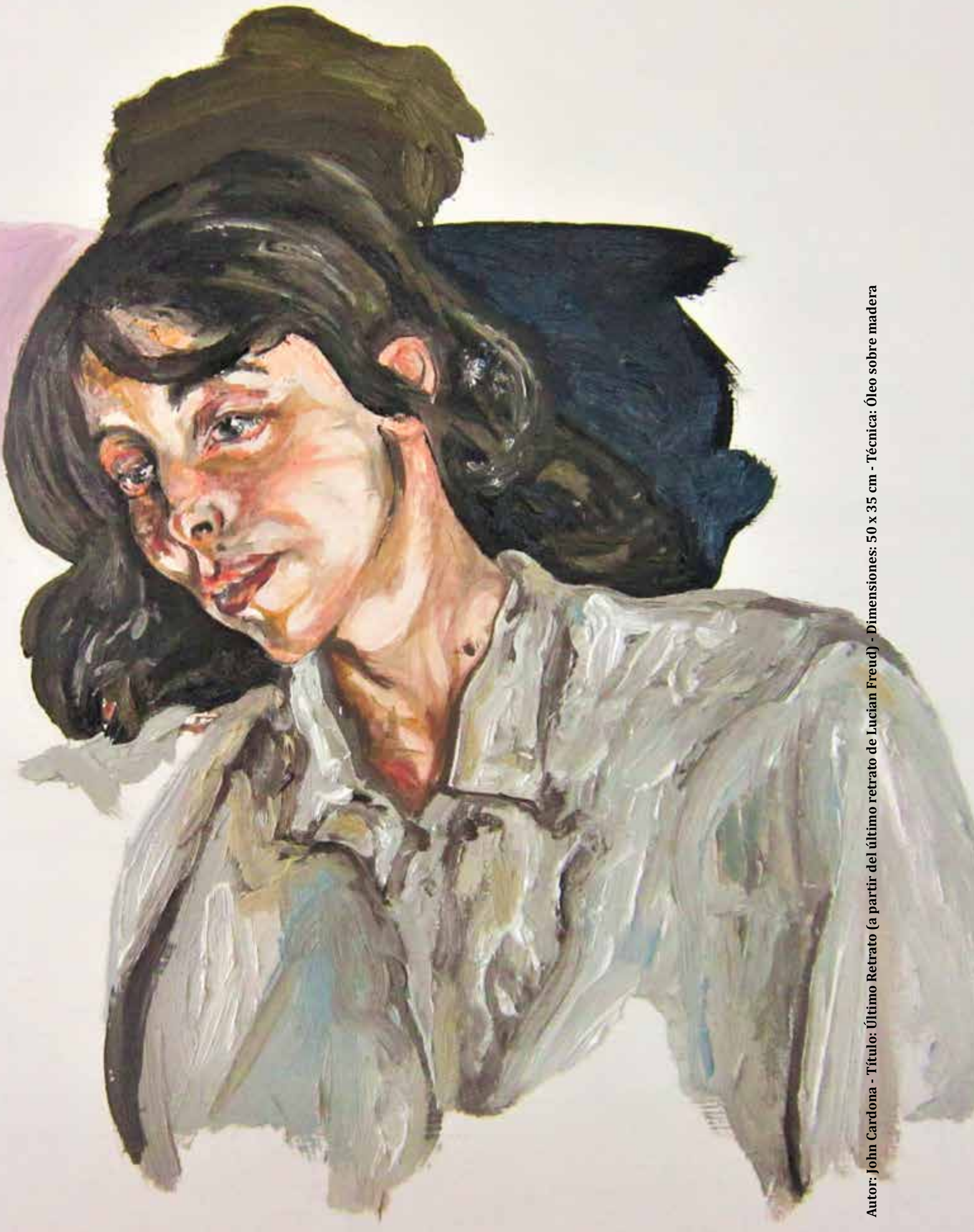

